\title{
Differential expression of microRNAs in tomato leaves treated with different light qualities
}

Fei Dong ${ }^{1,2}$, Chuanzeng Wang ${ }^{3}$, Yuhui Dong ${ }^{2}$, Shuqin Hao ${ }^{4}$, Lixia Wang ${ }^{5}$, Xiudong Sun $2,6,7^{*}$ and Shiqi Liu ${ }^{2,6,7^{*}}$

\begin{abstract}
Background: Light is the main source of energy and, as such, is one of the most important environmental factors for plant growth, morphogenesis, and other physiological responses. MicroRNAs (miRNAs) are endogenous noncoding RNAs that contain 21-24 nucleotides (nt) and play important roles in plant growth and development as well as stress responses. However, the role of miRNAs in the light response is less studied. We used tomato seedlings that were cultured in red light then transferred to blue light for 2 min to identify miRNAs related to light response by high-throughput sequencing.

Results: A total of 108 known miRNAs and 141 predicted novel miRNAs were identified in leaf samples from tomato leaves treated with the different light qualities. Among them, 15 known and 5 predicted novel miRNAs were differentially expressed after blue light treatment compared with the control (red light treatment). KEGG enrichment analysis showed that significantly enriched pathways included zeatin biosynthesis (k000908), homologous recombination (ko03440), and plant hormone signal transduction (ko04075). Zeatin biosynthesis and plant hormone signal transduction are related to plant hormones, indicating that plant hormones play important roles in the light response.
\end{abstract}

Conclusion: Our results provide a theoretical basis for further understanding the role of miRNAs in the light response of plants.

Keywords: Tomato, Light quality, MicroRNA, Target gene, Plant hormone

\section{Background}

Tomato (Solanum lycopersicum L.) is one of the main vegetables under protected cultivation and is an important part of the human diet. Tomato is also a model plant that has long been used in studies of plant genetics, development, physiology, pathology, and fleshy fruit ripening. Therefore, a lot of biological information about this important economic crop has accumulated [1].

MicroRNAs (miRNAs) are a class of endogenous noncoding RNAs that regulate gene expression at the posttranscriptional level by binding to complementary regions of the mRNAs of their target genes to degrade or inhibit the mRNAs [2,3]. Mature miRNAs are 21-24 nt long and are derived from pre-miRNAs that undergo

\footnotetext{
* Correspondence: xdsun@sdau.edu.cn; liusq99@sdau.edu.cn

${ }^{2}$ College of Horticulture Science and Engineering, Shandong Agricultural

University, Tai An 271018, China

Full list of author information is available at the end of the article
}

two cleavage steps catalyzed by Dicer-like 1 (DCL1) to produce miRNA:miRNA* double strands, which then form mature miRNAs after uncoiling [4]. MiRNAs not only regulate the development of leaf, flower, and fruit in tomato [5-9], but also are involved in the biotic and abiotic stress responses of tomato plants [2, 4, 10-13]. However, there are few reports on the roles of miRNAs in the light response.

Light is the main source of energy and is one of the most important environmental factors for plant growth, morphogenesis, and other physiological responses [14-16]. Light regulates germination, deetiolation, phototropism, flowering, leaf and stem growth, biological clock, stomatal opening, chloroplast relocation, and anthocyanin synthesis in plants $[17,18]$. Light quality is an important aspect of light research because it affects plant morphology and yield $[16,19]$, as well as plant quality $[19,20]$. Light 
quality regulates plant growth and development through various photoreceptors which stimulate signal transduction systems to change plant morphology $[19,21]$. Among them, red light can promote the growth of plants by promoting the elongation of hypocotyls, while blue light mainly inhibits the elongation and induction of hypocotyls [22, 23]. Blue light increases the net photosynthetic rate of tomato seedling leaves by inducing stomatal opening [24]; while red light reduces stomatal conductance and increases intercellular $\mathrm{CO}_{2}$ concentration, resulting in a decrease in photosynthetic rate [25]. In addition, red light inhibits the photosynthetic product from the leaves, which increases the starch accumulation of the leaves. The excessive accumulation of starch is not conducive to the photosynthesis of plant leaves [26].

The effects of light quality on plant miRNAs have been reported for soybean seedlings [27], callus of longan [28], Brassica rapa L. subsp. rapa cv. Tsuda [29], Arabidopsis thaliana [30, 31], and wheat [32]. However, the effect of different light qualities on the miRNAs of tomato seedlings has not been reported so far. In this study, we cultured tomato seedlings in red light then transferred some of them to blue light for $2 \mathrm{~min}$, and identified miRNAs related to the light signal response by high-throughput sequencing. The results will provide a theoretical foundation for further understanding the role of miRNAs in the light response of plants.

\section{Results}

Sequence analysis, and classification and annotation of the small RNAs (sRNAs)

A total of 67,554,747 and 69,317,206 raw reads were obtained from the leaves of tomato plants treated with red light (control) and blue light (treated), respectively. After removing the low-quality reads, $58,657,965$ (87.1\% of the total) and 59, 204,048 (85.4\% of the total) clean reads were obtained in the red light and blue light libraries, respectively (Table 1 ).

Note: S01, S02, S03 are red-treated tomato leaves, S04, S05, and S06 are blue-treated tomato leaves.

Most of the sRNAs in the red light and blue light libraries were unannotated, followed by those identified as
rRNAs. Only a small proportion of the sRNAs were identified as scRNAs, snRNAs, snoRNAs, or tRNAs (Fig. 1a). Generally, sRNAs are 18-30 nt long, and in the control and treated libraries, most of them were $24 \mathrm{nt}$ long, accounting for 36.57 and $38.90 \%$ of the total reads, respectively. Furthermore, most of the reads (90.16 and $89.52 \%$ ) in the control and treated libraries were $\leq 24$ nt (Fig. 1b).

\section{Identification of known miRNA}

We identified 108 known miRNAs in the two libraries, and 88 of them were from 39 miRNA families. The numbers of miRNAs in each family varied significantly; the most abundant family was MIR482 with 7 members, followed by the MIR171_1 and MIR156 families with 5 members each. Twenty families (MIR477, MIR833, MIR6023, MIR1120, MIR397, MIR399, MIR1516, MIR319, MIR4376, MiR6024, MIR5303, MIR160, MIR5304, MIR6022, MIR6026, MIR162_1, MIR8167, MIR169_2, MIR5208, and MIR5160) had only one member (Additional file 1: Table S1). The expression levels of different miRNAs varied significantly with counts ranging from 1 to 181,400 . Sly-miR159 was the most abundant with 137,039 and 129,853 counts in the control and treated libraries, respectively (Additional file 2: Table S2).

\section{Prediction of novel miRNAs}

We identified 141 candidate novel miRNAs in the two libraries, and 79 of them were from 56 miRNA families. The most abundant family was MIR398 with 9 members, followed by the MIR5303 and MIR400 families with 4 members each (Additional file 3: Table S3). Among the novel miRNAs, unconservative_1_3796 was the most abundant with 101,523 and 100,601 counts in the control and treated libraries, respectively (Additional file 2: Table S2).

\section{Differential expression of miRNAs}

Overall, we identified 249 miRNAs (108 known and 141 novel) in the two libraries. By comparing the expression levels of the miRNAs between the red light treated (control) and blue light treated libraries we identified 15 known and 5 novel miRNAs that were differentially expressed. Among them, 10 miRNAs (sly-miR169b, slymiR169e-5p, sly-miR5302a, sly-miR9472-3p, sly-miR9474-

Table 1 Quality control of the clean reads data

\begin{tabular}{|c|c|c|c|c|c|c|c|c|}
\hline Sample & Raw reads & Clean reads & Raw clean reads \% & Low quality \% & Containing ' $\mathrm{N}$ ' reads & Length $<18$ & Lenghth> 30 & Q30\% \\
\hline S01 & $27,670,941$ & $23,487,978$ & 84.88 & 0 & 0 & $2,173,796$ & $2,009,167$ & 98.46 \\
\hline S02 & $19,651,152$ & $17,574,787$ & 89.43 & 0 & 0 & 837,356 & $1,239,009$ & 98.70 \\
\hline S03 & $20,232,654$ & $17,595,200$ & 86.96 & 0 & 0 & $1,104,045$ & $1,533,409$ & 98.67 \\
\hline SO4 & $22,329,405$ & $18,822,750$ & 84.30 & 0 & 0 & $1,633,140$ & $1,873,515$ & 98.69 \\
\hline S05 & $25,943,329$ & $22,307,050$ & 85.98 & 0 & 0 & $1,236,511$ & $2,399,768$ & 98.51 \\
\hline S06 & $21,044,472$ & $18,074,248$ & 85.89 & 0 & 0 & 650,390 & $2,319,834$ & 98.49 \\
\hline
\end{tabular}

Note: S01, S02, S03 are red-treated tomato leaves, S04, S05, and S06 are blue-treated tomato leaves 

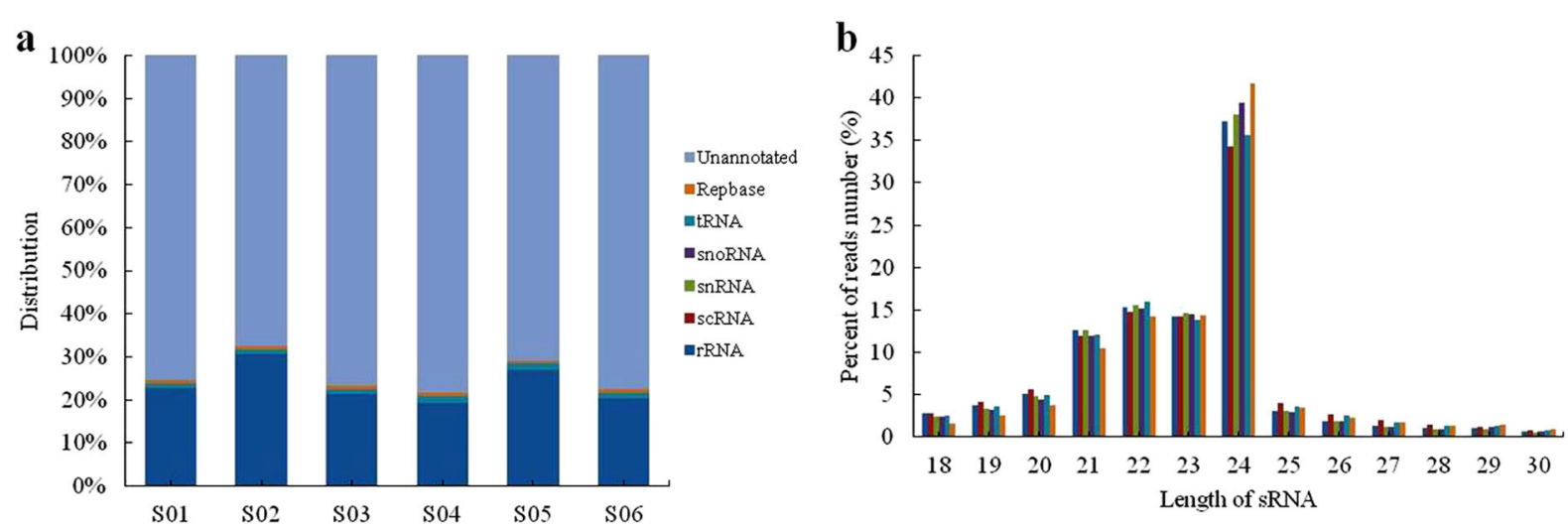

Fig. 1 Analysis of the small RNAs (sRNAs) in the blue light and red light treated libraries. a Classification of the sRNA sequences in the two libraries. b Length distribution of sRNA in the two libraries. S01, S02, S03 are red light treated tomato leaves; S04, S05, and S06 are blue light treated tomato leaves

5p, sly-miR9479-5p, unconservative_1_301, unconservative_5_19580, unconservative_9_35275, and unconservative_9_37129) were up-regulated, and 10 miRNAs (slymiR156e-3p, sly-miR156e-5p, sly-miR169c, sly-miR169d, sly-miR1918, sly-miR394-3p, sly-miR5302b-5p, sly-miR 9477-3p, sly-miR9478-5p, and sly-miR9478-5p) were down-regulated (Fig. 2; Additional file 4: Table S4).

\section{Prediction and functional analysis of the target genes of the differentially expressed miRNAs}

A total of 40 target genes of the 20 differentially expressed miRNAs were identified and functionally annotated with gene ontilogy (GO) terms and kyoto encyclopedia of genes and genomes (KEGG) pathways. Among them, 16 and 17 target genes were assigned GO terms and KEGG pathways, respectively. The GO analysis showed that under the biological process, cell component, and molecular function categories, metabolic process (GO: 0008152), membrane (GO:0016020), and catalytic activity (GO: 0003824) was the most enriched terms, respectively (Fig. 3). In the blue light treated library, DNA metabolic process (GO:0006259), bounding membrane of organelle (GO:0098588), and nucleic acid binding (GO:0003676) were significantly enriched (Additional file 5: Table S5).

The KEGG analysis showed that the 17 annotated target genes were associated with 9 metabolic pathway, and pathways that contained several target genes were obviously enriched, namely zeatin biosynthesis (ko00908), homologous recombination (ko03440), and plant hormone signal transduction (ko04075) (Fig. 3, Additional file 6: Table S6).

\section{Verification of differentially expressed miRNAs and target genes}

The expression levels of the 20 differentially expressed miRNAs and 10 randomly selected target genes were verified by quantitative reverse transcription PCR (qRTPCR). The expression patterns of the miRNAs determined by qRT-PCR were consistent with those from the Illumina RNA sequencing data, and the expression patterns of the 10 target genes were opposite to those of the corresponding miRNAs (Fig. 4). For example, target genes Solyc06g068930.1 and Solyc08g082260.1 were down-regulated under blue light, whereas their corresponding miRNAs were up-regulated (Fig. 4b).

\section{Discussion}

As non-coding small RNAs, miRNAs play important roles in plant growth and development, and stress response $[2,4,8,11,13]$. Previous studies have shown that miRNA regulate many stress-related genes, including those encode dehydrins, late embryo abundant proteins (LEA), glutathione S-transferase (GST), transcription factors (GRAS, ARF and MYB), and hormonal pathway components [4]. With the development of nextgeneration sequencing technology, high-throughput sequencing has been widely used to identify conserved and novel miRNAs in plants [4, 33, 34]. However, there are few reports about the effect of light quality on tomato miRNAs. In addition, studies have shown that the earliest significant changes we detected in almost all tissue types sampled initiated at 1 or $2 \mathrm{~min}$ post high light stress application to the local leaf [35]. Therefore, in this study, tomato seedlings were cultured in red light then some were transferred to blue light for $2 \mathrm{~min}$. Then the red light treated (control) and blue light treated libraries were compared to detect miRNAs related to light signals.

The sequencing results showed that $24 \mathrm{nt}$ long sRNAs were the most abundant in the control and blue light treated libraries, accounting for 36.57 and $38.90 \%$ of the total reads respectively. This finding is consistent with previous studies in tomato $[2,4,8,11]$. It has been 


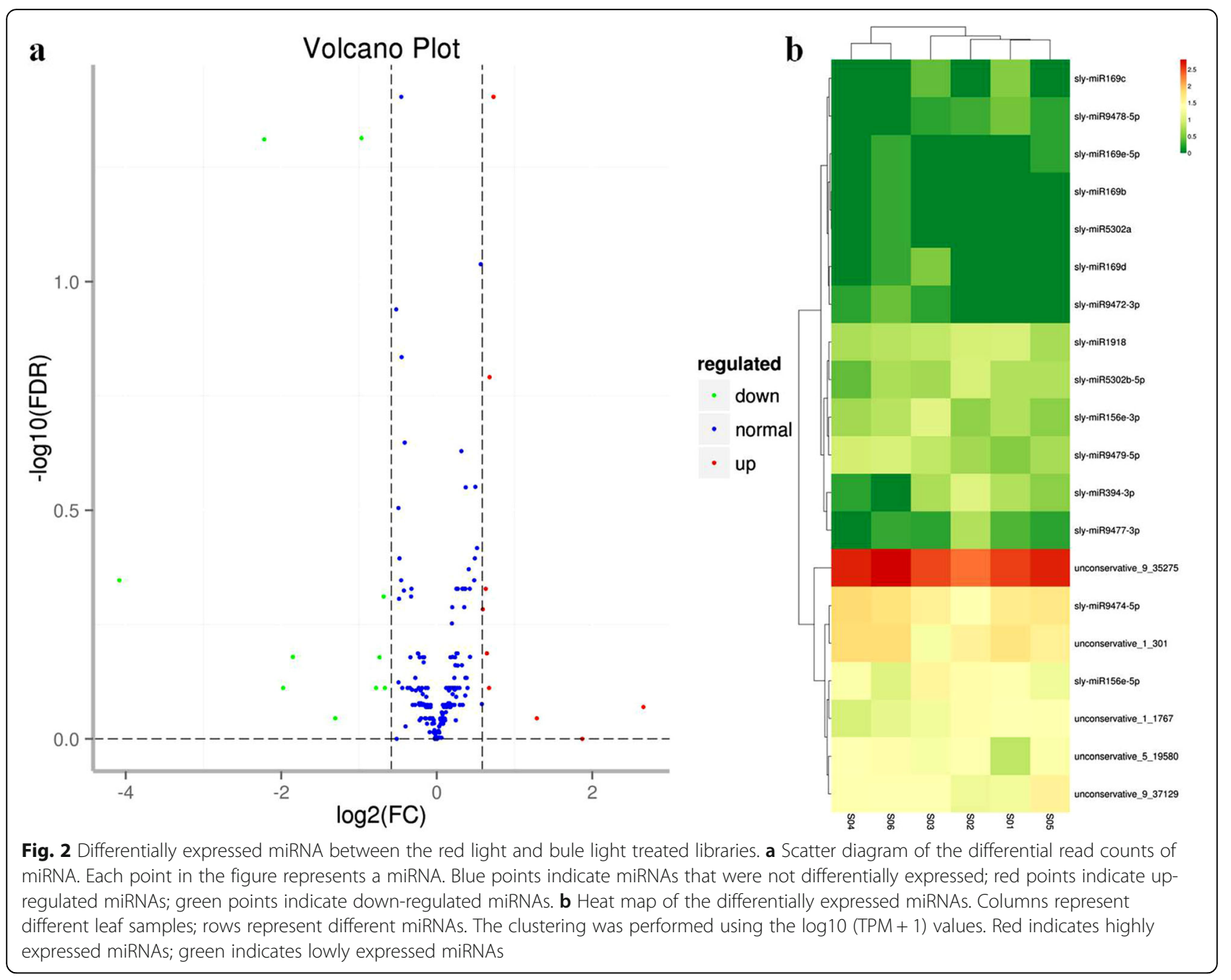

reported that $24 \mathrm{nt}$ sRNAs play important roles in transcriptional silencing of transposon and pericentromeric regions through RNA-directed DNA methylation [11].

We detected 249 miRNAs in the two libraries. Of the 108 known miRNAs, 88 belonged to 39 families. The number of miRNAs in each family varied greatly, with the MIR482 family having the most members. The expression levels of different miRNAs also varied greatly, with counts ranging from 1 to 181,400 . Sly-miR159 was the most highly expressed, which is consistent with previous results $[4,36]$. Of the 141 novel miRNAs, 79 belonged to 56 families, and the MIR398 family had the most members. Unconservative_1_3796 was the most highly expressed of the novel miRNAs, having 101,523 and 100,601 counts in the red light control and blue light treated libraries, respectively (Additional file 2: Table S2).

The important regulatory function of miRNAs in controlling the expression of photoresponse genes has been reported previously. For example, Pashkovskiy et al. [37] reported that blue light significantly increased the expression of miR167, which reduced the expression of its target genes $A R F 6$ and $A R F 8$, thereby reducing the activation of auxin-dependent genes. Zhou et al. [29] showed that during the development of Brassica rapa subsp. Rapa cv. Tsuda seedlings, blue light specifically down-regulated miR156 and miR157, and up-regulated the target genes SPL9 and SPL15. Li et al. [38] reported that blue light inhibited the expression of miR394, which promoted the expression of the target genes and the accumulation of flavonoids and epicatechins, but inhibited the synthesis of rutin. We found that sly-miR156e-3p, sly-miR156e-5p, and sly-miR394-3p were significantly down-regulated in the blue light treated leaves, which is consistent with the above research results. In addition, 20 miRNAs (15 known and 5 novel) belonging to 8 families (MIR169_2, MIR169_1, MIR5302, MIR1516, MIR156, MIR394, MIR837, and MIR8005) were differentially expressed in the blue light treated leaves; 10 were up-regulated (sly-miR169b, sly-miR169e-5p, slymiR5302a, sly-miR9472-3p, sly-miR9474-5p, sly-miR94795p, unconservative_1_301, unconservative_5_19580, uncon servative_9_35275, and unconservative_9_37129) and 10 were down-regulated (sly-miR156e-3p, sly-miR156e-5p, sly- 


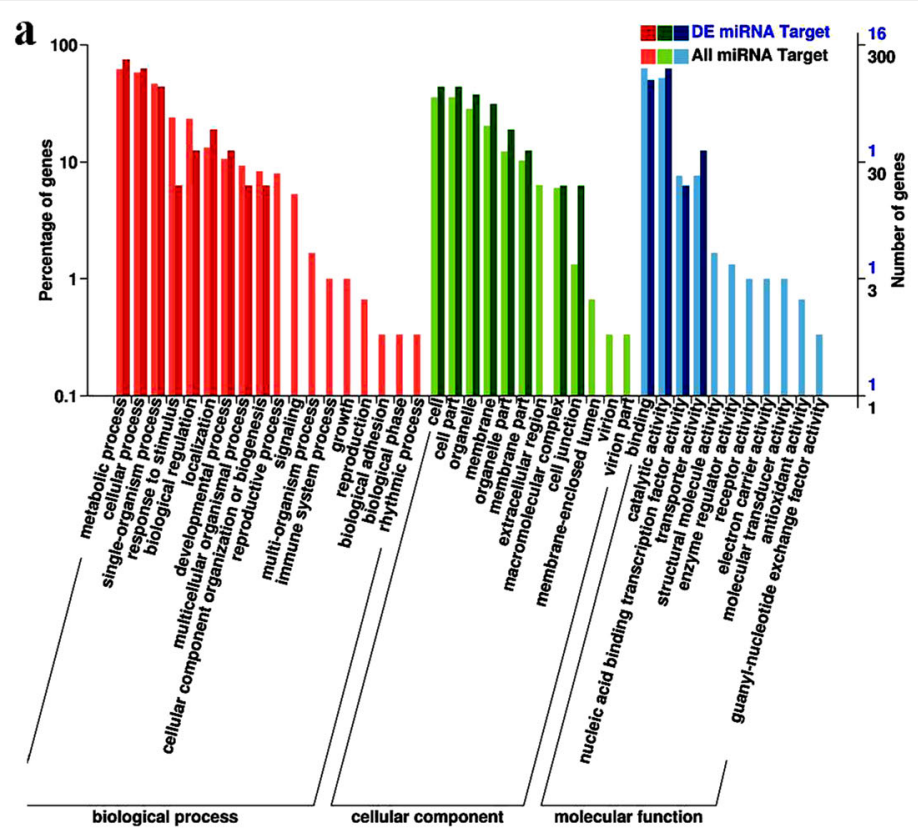

b

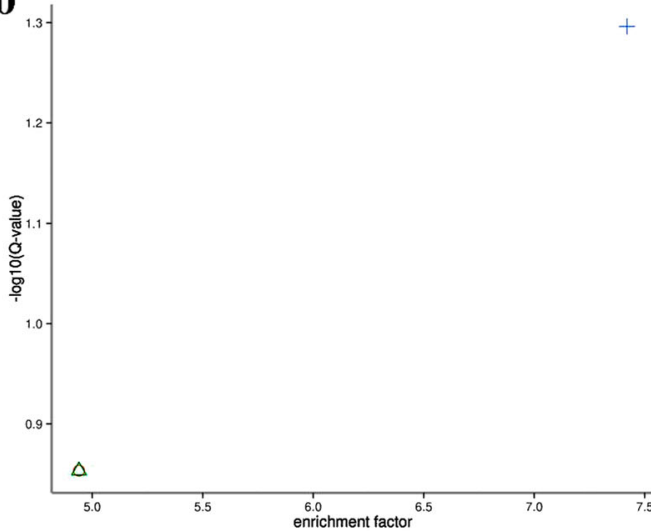

C

KEGG_pathway

Homologous recombination

$\triangle$ Plant hormone signal transouction

+ Zeatin biosynthesis

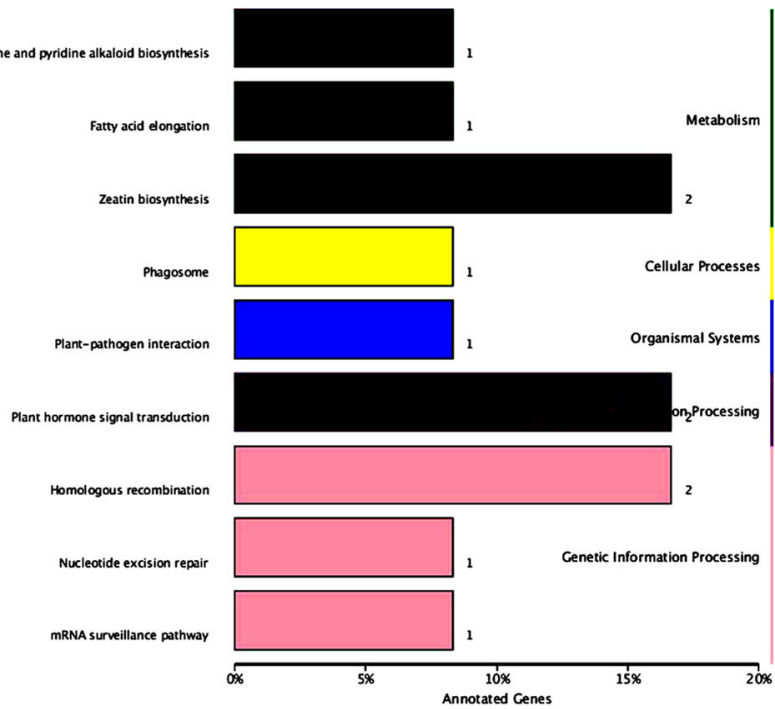

Fig. 3 (See legend on next page.) 
(See figure on previous page.)

Fig. 3 Gene ontology (GO) classification and kyoto encyclopedia of genes and genomes (KEGG) analysis of target genes of the differentialy expressed miRNAs. a GO annotation of 16 candidate target genes. The $x$-axis indicates the $\mathrm{GO}$ category; the right $\mathrm{y}$-axis indicates the number of target genes in a category; the left $y$-axis indicates the percentage of target genes annotated with a specific term under the main category. $\mathbf{b}$ KEGG pathway enrichment scatter plot of 17 candidate target genes. Each graph represents a KEGG pathway and the pathway name is shown in the right graph. The abscissa is the enrichment factor, indicating the proportion of the number of differentially expressed miRNA target genes annotated to a certain pathway in the total number of genes annotated to this pathway. The larger the enrichment factor, the more significant the level of enrichment of differentially expressed miRNA target genes in this pathway. The ordinate is $-\log 10(\mathrm{Q}$ value), where $Q$ is the $P$ value after correction by the multiple hypothesis test. Thus, the larger the ordinate, the more reliable the significance of the enrichment of the differentially expressed miRNA target gene in this pathway. c KEGG classification map of the target genes of the differentialy expressed miRNAs. The ordinate is the KEGG metabolic pathway; the abscissa is the number of genes annotated to the pathway and their proportion to the total number of genes annotated

miR169c, sly-miR169d, sly-miR1918, sly-miR394-3p, slymiR5302b-5p, sly-miR9477-3p, sly-miR9478-5p and unconservative_1_1767).

Plant hormones are important regulators of plant growth, development, and stress responses [4, 39]. Previous studies have shown that plant hormone signal transduction pathways were involved in the growth and development of sugarcane [36], maize [40], and radish [41], as well as in the responses to pathogenic microorganism infection [42-44], salt stress [45], and drought $[46,47]$. In this study, the KEGG enrichment analysis showed that plant hormone signal transduction pathways not only contained more target genes, but also were obviously enriched. Our results showed that the differentially expressed miRNAs sly-miR $169 \mathrm{~b}$ and slymiR9474-5p targeted genes that encode TIFY protein and protein phosphatase $2 \mathrm{C}$ (PP2C), respectively, which are involved in plant hormone signal transduction pathways (Additional file 6: Table S6). TIFYs are plantspecific transcription factors that are encoded by multiple genes and are highly conserved, especially the core motif TIF [F/Y] XG $[48,49]$. Members of the TIFY protein family are involved in many biological processes. For example, overexpression of AtTIFY1 (also known as
ZIM) in Arabidopsis thaliana led to the extension of the petiole and hypocotyls [50], overexpression of AtTIFY4a (also known as PPD1) and AtTIFY4b (also known as $P P D 2)$ contributed to the synchronous growth of Arabidopsis leaves [51], and overexpression of $J A Z$ affected the response to biotic and abiotic stresses through mediating jasmonic acid signal transduction [52-55]. PP2C is a protein serine/threonine phosphatase and a key enzyme in the regulation of reversible protein phosphorylation. PP2C is present as a monomer in cells and its catalytic activity is $\mathrm{Mg}^{2+}$ or $\mathrm{Mn}^{2+}$ dependent. Reversible phosphorylation catalyzed by protein kinases and protein phosphatases is an important component of signal transduction, which is required for almost all physiological and pathological processes. In plants, PP2C is closely related to signal transduction [56], growth and development [57]; response to abiotic stresses such as drought [58], low temperature [59], high salt [60], and mechanical damage [61]; biotic stresses such as bacterial infection [62].

Zeatin is a cytokinin that plays an important role in cell division. The blue light responding sly-miR9472-3p foung in this study targeted the gene encoding adenylate isopentenyltransferase 5 , which is associated with the

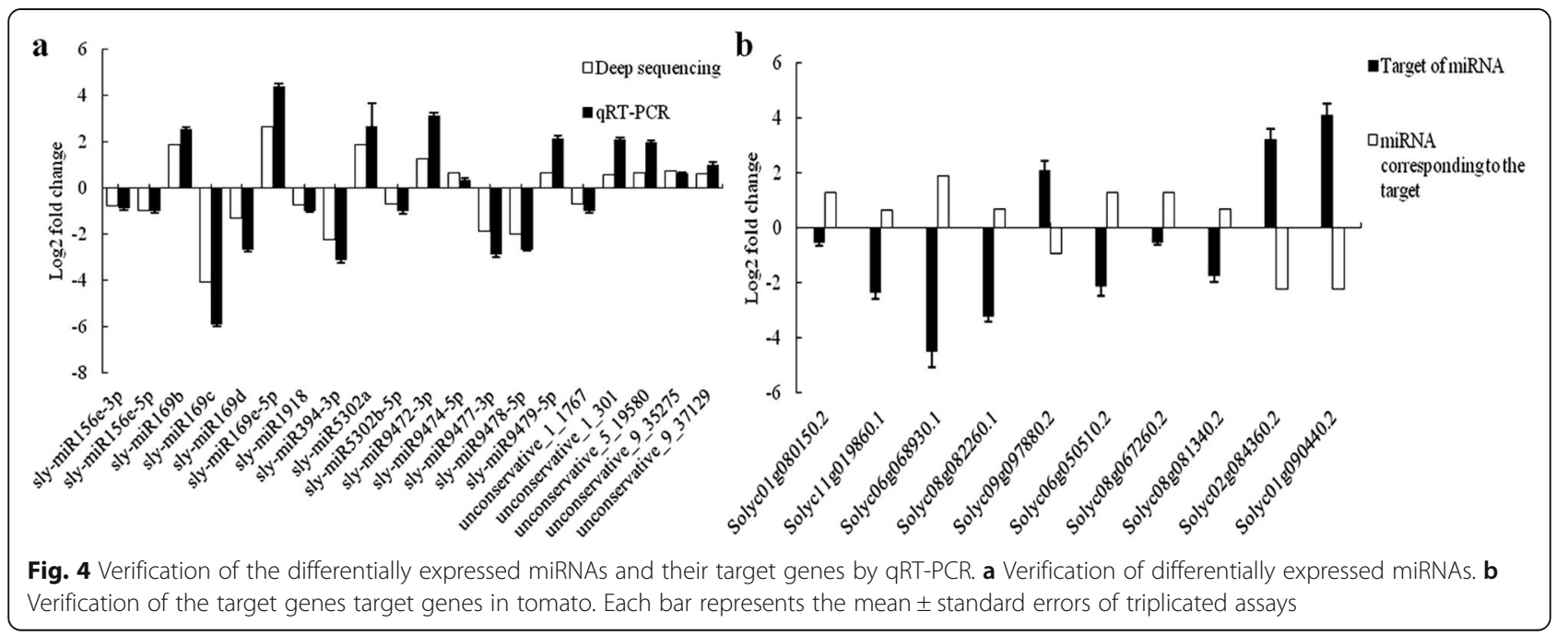


zeatin biosynthesis signaling pathway (Additional file 6: Table S6). Adenylate isoamyltransferase, a rate-limiting enzyme in cytokinin synthesis, catalyzes the transfer of the isopentenyl group of dimethylallyl pyrophosphate to the amino terminal $\mathrm{N}^{6}$ of ATP, ADP, and AMP. In addition to their catalytic function, some adenylate isoamyltransferases have stress resistance functions. In tomato plants, two isopentenyltransferases (SIIPT3 and SIIPT4) were found to be involved in the response to salt stress [63]. In Clematis paniculata, adenylate isopentenyltransferase was associated with responses to external stresses (UV-B, salt stress, and drought) [64]. The reduction of endogenous cytokinins in Arabidopsis was shown to enhance plant salt and cold tolerance [65]. We suggest the up-regulation of sly-miR9472-3p may inhibit the activity of adenylate isoamyltransferase, thereby decreasing cytokinin levels and enhancing the plant tolerance. Zeatin biosynthesis and plant hormone signal transduction are both signaling pathways related to plant hormones, which indicates that plant hormones play very important roles in the light response of plants.

\section{Conclusions}

We identified 108 known miRNAs and 141 candidate novel miRNAs. Among them, 15 known and 5 novel miRNAs were differentially expressed in tomato leaves after blue light treatment. KEGG enrichment analysis of the target genes revealed that the zeatin biosynthesis (ko00908), homologous recombination (ko03440), and plant hormone signal transduction (ko04075) pathways were obviously enriched. Zeatin biosynthesis and plant hormone signal transduction both are related to plant hormones, which indicates plant hormones play a very important role in the light response. Our results provide a theoretical basis for further understanding the role of miRNAs in light response.1.

\section{Methods}

\section{Test materials and treatments}

We used tomato Solanum lycopersicum L. cv Micro-Tom (Pan American Seed, USA) as the test material. Germinated seeds were sown in a substrate containing vermiculite and peat $(1: 2, \mathrm{~V}: \mathrm{V})$, then grown in a greenhouse. When the second true leaf had fully expanded, the same growth conditions were selected and transferred to the light quality laboratory of Scientific and Technological Innovation Park in Shandong Agriculture University and grown in the same substrate under red light $(657 \mathrm{~nm})$ until the five-leaf stage. Then, half of the seedlings were transferred to blue light $(457 \mathrm{~nm})$ for $2 \mathrm{~min}$. The seedlings treated with red light were used as the control. The second leaf from the bottom of the tomato seedlings treated with red and blue light was removed and frozen in liquid nitrogen, then stored at $-80^{\circ} \mathrm{C}$ for further experiments.
The LED light source was provided by Guangdong Chunying Photoelectric Technology Co., LTD. The light treatment scaffold was made of steel, and the light source was placed on the top. The scaffold was covered with silver shading cloth to ensure the LED light was the only light source for plant growth. Each treatment was completed with 50 seedlings, and all experiments were conducted in triplicate; the plants were arranged randomly. Photosynthetic photon flux density (PPFD) at 50 $\mathrm{cm}$ from the light source was $300 \mu \mathrm{mol} \cdot \mathrm{m}^{-2} \cdot \mathrm{s}^{-1}$, tomato plants were incubated under a 12 -h light $\left(28^{\circ} \mathrm{C}\right): 12$-h dark $\left(18^{\circ} \mathrm{C}\right)$ photoperiod, and the relative humidity was $70 \% \pm 10 \%$.

\section{MiRNA isolation, library construction, and Illumina sequencing}

Total RNA was extracted from the tomato leaves using a Trizol kit (Invitrogen, CA, USA) and purified using a miRNeasy Mini kit (Qiagen, Germany). The concentration and quality of the RNA samples were detected using a Nanodrop 2000 spectrophotometer (Thermo Fisher scientific, Wilmington, USA). The RNA libraries were constructed using a NEB Next Ultra small RNA Sample Library Prep Kit for Illumina strictly according to the manufacturer's instructions. For each qualified RNA sample, $1.5 \mu \mathrm{g}$ of RNA was supplemented to $6 \mu \mathrm{L}$ by water, then the library was constructed using a small RNA Sample Preparation Kit. Adapters were added to the 5' (phosphate group) and 3' (hydroxyl group) ends of the sRNAs by T4 RNA ligase 1 and T4 RNA ligase 2 (truncated), respectively. The sequences with adaptors were used for CDNA synthesis and PCR amplification. The target fragments were screened by gel purification, and the fragments recovered from the gel were used to establish the sRNA libraries. The concentration of the sRNAs in each library was detected using Qubit 2.0, then they were diluted to $1 \mathrm{ng} . \mu \mathrm{L}^{-1}$. The insert size was detected using an Agilent 2100 Bioanalyzer and the effective concentration of each library was measured by qRT-PCR to ensure the quality of the library. The qRTPCR program was as follows: $95^{\circ} \mathrm{C}$ for $5 \mathrm{~min}$; 35 cycles of $95^{\circ} \mathrm{C}$ for $30 \mathrm{~s}, 60{ }^{\circ} \mathrm{C}$ for $45 \mathrm{~s}$, and $95^{\circ} \mathrm{C}$ for $5 \mathrm{~s}$. Highthroughput sequencing of the libraries was carried out using an Illumina's HiSeq X-Ten system, with single-end read length of $50 \mathrm{nt}$.

\section{Sequencing data analysis}

The raw sequencing data were filtered to obtain clean reads for bioinformatics analysis. First, reads with 10\% or higher unknown $\mathrm{N}$ bases and reads without the 3' adaptor or insert sequences were removed. Then, the 3 ' adaptor sequences and reads $<18 \mathrm{nt}$ or $>30 \mathrm{nt}$ were removed. 
Bowtie [66] was used to BLAST the clean reads against four databases: SILVA, GtRNAdb, Rfam, and Repbase. Candidate miRNAs were obtained by filtering out reads that were identified as ribosomal RNA (rRNA), translocation RNA (tRNA), small nuclear RNA (snRNA), small nucleolar RNA (snoRNA), or repetitive sequences.

\section{Identification of known and novel miRNAs}

We used the miRDeep2 (v2.0.5) package [67] to compare reads that were aligned to the tomato reference genome with known miRNA precursor sequences in the miRBase database. Reads that were identical to sequences in miRBase were considered to be known miRNAs. Potential miRNA precursor sequences were obtained by aligning the reads to the tomato genome sequence. Reads that did not find matches in miRBase were identified as novel miRNAs by Bayesian model grading based on the location of the reads in the precursor sequence (including mature, star, and loop) and the energy of the precursor structure determined by RNAfold randfold. The reparameterized miRDeep2 is invoked. The length of sequences for predicting RNA secondary structure is set to 250 , and a plant-specific scoring system is added to miRDeep2 [67]. Although miRDeep2 has been used mainly to identify animal miRNAs [67], it has been used to identify plant miRNAs after adjusting the parameters and grading system [68].

\section{Screening of differentially expressed miRNAs}

MiRNA expression in each library was normalized using the two-phase multi-cast (TPM) algorithm [69] as follows: $\mathrm{TPM}=$ number of reads that mapped to one miRNA $\times 1,000,000 /$ number of reads that mapped to all miRNAs. The differentially expressed miRNAs between the two libraries were obtained using DESeq [70] with the screening criteria set as $|\log 2(\mathrm{FC})| \geq$ 0.584962500721156 and False discovery rate (FDR) $\leq 1$. The fold change (FC) indicates the ratio of the expression levels in the two libraries.

\section{Prediction of miRNA target genes, and GO and KEGG pathway functional analysis}

TargetFinder was used to predict the miRNA target genes [71]. The functions of the target genes were predicted by BLAST searches against the GO [72] and KEGG [73] databases.

Table 2 Primers used for qRT-PCR verification of the miRNAs and target genes

\begin{tabular}{|c|c|c|c|}
\hline Primer name & Sequence $\left(5^{\prime}-3^{\prime}\right)$ & Primer name & Sequence $\left(5^{\prime}-3^{\prime}\right)$ \\
\hline sly-miR156e-3p & GCTTACTCTCTATCTGTCACC & Solyc01g080150.2-F & TCCTCCTTCATCGTCAAC \\
\hline sly-miR156e-5p & TAGCCAAGGATGACTTGCCTG & Solyc01g080150.2-R & AGAGTAGTAGTTCCATTCTTCC \\
\hline sly-miR169b & CAGCCAAGGATGACTTGCCGA & Solyc11g019860.1-F & CAAGCGTAATACTCGTATGT \\
\hline sly-miR169c & TAGCCAAGGATGACTTGCCTA & Solyc11g019860.1-R & GCTTCGTCAGTATCTTCTTC \\
\hline sly-miR169d & TAGCCAAGGATGACTTGCCTIT & Solyc06g068930.1-F & TCAAGAATCTCGTCAACCT \\
\hline sly-miR169e-5p & TGTTGGTGAGAGTTCGATTCTC & Solyc06g068930.1-R & GCAGCAGGAAGTGAAGTA \\
\hline sly-miR1918 & TGTTGGTGAGAGTTCGATTCTC & Solyc08g082260.1-F & GTAGTCGTGGTGTTGCTA \\
\hline sly-miR394-3p & AGGTGGGCATACTGTCAACA & Solyc08g082260.1-R & CTGGCTCTGGTATCACAA \\
\hline sly-miR5302a & AAACGAGGTTTGTACTTTGG & Solyc09g097880.2-F & CTGGCTATTAGTGAGAAGAATC \\
\hline sly-miR5302b-5p & TGAAATGCTATAGTTGGAAAGT & Solyc09g097880.2-R & GACGCATCTGTTCCAATAC \\
\hline sly-miR9472-3p & TTCACAATCTCTGCTGAAAAA & Solyc06g050510.2-F & GAGAGGTGGCTGTGTTAT \\
\hline sly-miR9474-5p & TGTAGAAGTCATGAATAAAATG & Solyc06g050510.2-R & CCAGGTGTAGAGTGTTGT \\
\hline sly-miR9477-3p & TTGGGAAAGGGAACAACTGATAGT & Solyc08g067260.2-F & AGTAGAAGTTGGAGGAGATG \\
\hline sly-miR9478-5p & GCTTAAATATGTAGATCGAACT & Solyc08g067260.2-R & AGACACAGAAGTGCTCAA \\
\hline sly-miR9479-5p & TCCAGTCCTCTACCCTTCTCCA & Solyc08g081340.2-F & ATAGGATGGCAGGAGGTA \\
\hline unconservative_1_1767 & AAGAAAAACGACUGAAUAUAAAUC & Solyc08g081340.2-R & CAAGACGATGGTAAGACAAC \\
\hline unconservative_1_301 & AUUGCGAUGAUUAUGUUCAACCCU & Solyc02g084360.2-F & GCTTGATAACCGATGCTAG \\
\hline unconservative_5_19580 & AUGGUGUCUGGCUGUUAUUUCAGC & Solyc02g084360.2-R & GATGCGACTCATTATTGGAA \\
\hline unconservative_9_35275 & AUAUACAAAUUUCUGCUCAUUUCG & Solyc01g090440.2-F & GAGATGACTATGAAGAGGATGA \\
\hline unconservative_9_37129 & AUCUGUAUCUAGAAUUCAAAGUCU & Solyc01g090440.2-R & GAAGAGGATATTGGTGAGATTG \\
\hline U6 & AACAGTCTGACTTGTCCCTTC & Actin4-F & GAGGATATTCAGCCCCTTGTTTG \\
\hline Universal reverse primer & $\begin{array}{l}\text { GCATAGACCTGAATGGCGGTAAGG } \\
\text { GTGTGGTAGGCGAGACATIIIIIIIIIIIIIIIIIा }\end{array}$ & Actin4-R & CATCTITCTGACCCATTCCAACC \\
\hline
\end{tabular}




\section{Verification of miRNAs and target genes by qRT-PCR} The expressions of 20 of the differentially expressed miRNAs and the corresponding 10 major target genes were detected by qRT-PCR. A SYBR ${ }^{\circ}$ PrimeScript $^{\text {tw }}$ miRNA RT-PCR kit (TaKaRa) was used to produce the cDNA. Specific primers for the target genes were designed using Beacon Designer 7.9 (Table 2). The qRTPCR cycle was as follows: preheat at $95^{\circ} \mathrm{C}$ for $30 \mathrm{~s}$; $40 \mathrm{cy}$ cles of denaturation at $95{ }^{\circ} \mathrm{Cfor} 20 \mathrm{~s}$, then annealing at $60^{\circ} \mathrm{C}$ for $20 \mathrm{~s}$. Amplification curve and melting curve analyses $\left(95^{\circ} \mathrm{C}\right.$ for $60 \mathrm{~s}, 55^{\circ} \mathrm{C}$ for $30 \mathrm{~s}$, and $95^{\circ} \mathrm{C}$ for $30 \mathrm{~s}$ ) were carried out to ensure the specificity of the products. All reactions were repeated three times. U6 and Actin4 (Solyc04g 011500) were used as the internal reference genes, and all data were analyzed using the $2^{-\Delta \Delta \mathrm{Ct}}$ method.

\section{Supplementary information}

Supplementary information accompanies this paper at https://doi.org/10. 1186/s12864-019-6440-4

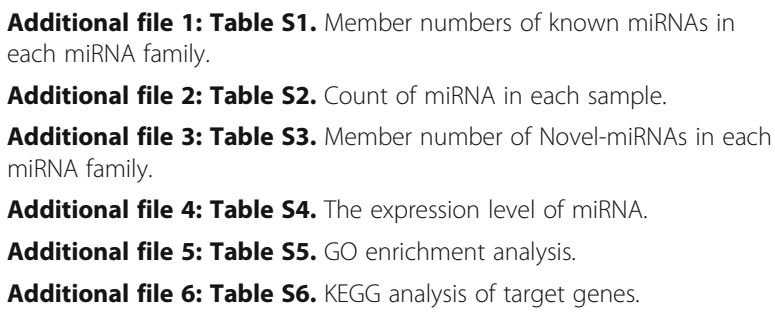

\section{Abbreviations}

DCL1: Dicer-like 1; FC: Fold change; FDR: False discovery rate; GO: Gene ontilogy; GST: Glutathione S-transferase; KEGG: Kyoto encyclopedia of genes and genomes; LEA: Late embryo abundant; miRNAs: MicroRNAs; nt: Nucleotide; PP2C: Protein phosphatase 2C; qRT-PCR: Quantitative reverse transcription PCR; rRNA: Ribosomal RNA; snoRNA: Small nucleolar RNA; snRNA: Small nuclear RNA; sRNAs: small RNAs; tRNA: Translocation RNA

\section{Acknowledgments}

We thank Margaret Biswas, PhD, from Liwen Bianji, Edanz Group China (www. Liwenbianji.cn/ ac), for editing the English text of a draft of this manuscript. We are grateful to all co-authors who participated in the studies mentioned in the text that were published by our groups. All authors declared no conflict of interest.

\section{Authors' contributions}

FD and SQL conceived and designed the research. FD performed the experiments and wrote the manuscript. FD and CZW analyzed the data, and CZW formatted and revised the manuscript. LXW and YHD contributed in the retrieval of genes and the analysis of qRT-PCR results. SQH contributed in designing qRT-PCR primers. XDS and SQL supervised the project as co- correspondence. All authors have read and approved the final manuscript.

\section{Funding}

This work was supported by the Special Fund for Shandong Provincial Natural Science Foundation [grant number ZR2016CM33], the National Natural Science Foundation of China [grant number 31772323], and Agroscientific Research in the Public Interest [grant number 201303108]. The funding institutions had no direct role in study design, sample collection, analysis, and interpretation of date, nor in manuscript writing. Annual reports were submitted to the funding institutions tracking the progressof the projects.

\section{Availability of data and materials}

The dataset supporting the conclusions of this article is available in the NCBI's BioProject database [PRJNA523681].

\section{Ethics approval and consent to participate}

The tomato fruits were cultivated and collected in the light quality laboratory of Scientific and Technological Innovation Park in Shandong Agriculture University. The authors declared the compliance with institutional, national and international guidelines. The experiment was environmentally friendly and had no negative effects on the local ecosystem.

\section{Consent for publication}

Not applicable.

\section{Competing interests}

The authors declare that they have no competing interests.

\section{Author details}

${ }^{1}$ Vegetable and Flower Research Institute of Shandong Academy of Agricultural Sciences / Shandong Key Laboratory of Greenhouse Vegetable Biology / Shandong Branch of National Vegetable Improvement Center / Vegetable Science Observation and Experimental Station in Huang-Huai District of the Ministry of Agriculture, Jinan 250100, China. ${ }^{2}$ College of Horticulture Science and Engineering, Shandong Agricultural University, Tai An 271018, China. ${ }^{3}$ Shandong Academy of Agricultural Sciences, Jinan 250100, China. ${ }^{4}$ Shandong Agriculture and Engineering University, Jinan 250100, China. ${ }^{5}$ Shenyang Agriculture University, Shenyang 110866, China. ${ }^{6}$ State Key Laboratory of Crop Biology, Tai An 271018, China. ${ }^{7}$ Ministry of Agriculture Key Laboratory of Biology and Genetic Improvement of Horticultural Crops in Huanghuai Region, Tai An 271018, China.

Received: 22 February 2019 Accepted: 29 December 2019

Published online: 13 January 2020

\section{References}

1. Faurobert M, Mihr C, Bertin N, Pawlowski T, Negroni L, Sommerer N, Causse M. Major proteome variations associated with cherry tomato pericarp development and ripening. Plant Physiol. 2007;143:1327-46.

2. Pentimone I, Lebrón R, Hackenberg M, Rosso LC, Colagiero M, Nigro F, Ciancio A. Identification of tomato miRNAs responsive to root colonization by endophytic Pochonia chlamydosporia. Appl Microbiol Biotechnol. 2018; 102:907-19.

3. Li SX, Shao ZR, Fu X, Xiao W, Li L, Chen M, Sun MY, Li DM, Gao DS. Identification and characterization of Prunus persica miRNAs in response to UVB radiation in greenhouse through high-throughput sequencing. BMC Genomics. 2017;18:938.

4. Liu MM, Yu HY, Zhao GJ, Huang QF, Lu YG, Ouyang B. Identification of drought- responsive microRNAs in tomato using high-throughput sequencing. Funct Integr Genomics. 2018;18:67-78.

5. Ori N, Cohen AR, Etzioni A, Brand A, Yanai O, Shleizer S, Menda N, Amsellem Z, Efroni I, Pekker I, Alvarez JP, Blum E, Zamir D, Eshed Y. Regulation of LANCEOLATE by miR319 is required for compound-leaf development in tomato. Nat Genet. 2007;39:787-91.

6. Korir NK, Li XY, Xin S, Wang C, Changnian S, Kayesh E, Fang JG. Characterization and expression profiling of selected microRNAs in tomato (Solanum lycopersicon) 'Jiangshu14'. Mol Biol Rep. 2013;40:3503-21.

7. Lopez-Gomollon S, Mohorianu I, Szittya G, Moulton V, Dalmay T. Diverse correlation patterns between microRNAs and their targets during tomato fruit development indicates different modes of microRNA actions. Planta. 2012;236(6):1875-87.

8. Pan CT, Ye L, Zheng Y, Wang Y, Yang DD, Liu Y, Chen L, Zhang YW, Fei ZJ, Lu G. Identification and expression profiling of microRNAs involved in the stigma exsertion under high-temperature stress in tomato. BMC Genomics. 2017;18:843.

9. Karlova R, van Haarst JC, Maliepaard C, van de Geest H, Bovy AG, Lammers $M$, Angenent GC, de Maagd RA. Identification of microRNA targets in tomato fruit development using high-throughput sequencing and degradome analysis. J Exp Bot. 2013;63(7):1863-78.

10. Gu M, Xu K, Chen AQ, Zhu YY, Tang GL, Xu GH. Expression analysis suggests potential roles of microRNAs for phosphate and arbuscular mycorrhizal signaling in Solanum lycopersicum. Physiol Plant. 2010;138(2):226-37. 
11. Wang KT, Su XM, Cui X, Du YC, Zhang SB, Gao JC. Identification and characterization of microRNA during Bemisia tabaci infestations in Solanum lycopersicum and Solanum habrochaites. Horticultural Plant J. 2018;4(2):62-72.

12. Luan YS, Cui J, Zhai JM, Li J, Han L, Meng J. High-throughput sequencing reveals differential expression of miRNAs in tomato inoculated with Phytophthora infestans. Planta. 2015;241:1405-16.

13. Kumar G, Singh A, Vinutha T, Kumar S, Kumar RR, Praveen S. Possible role of miRNAs and their targets, in modulating leaf morphology and plant growth during leaf curl virus infection in tomato. Ind J Plant Physiol. 2017;22(4):608-15.

14. Fukuda N, Fujitan M, Ohta Y, Sase S, Nishimura S, Ezura H. Directional blue light irradiation triggers epidermal cell elongation of abaxial side resulting in inhibition of leaf epinasty in geranium under red light condition. J Hort Sci. 2008;115:176-82.

15. Li Q, Kubota C. Effects of supplemental light quality on growth and phytochemicals of baby leaf lettuce. J Environ Exp Bot. 2009;67:59-64.

16. Fan XX, Xu ZG, Liu XY, Tang CM, Wang LW, Han XL. Effects of light intensity on the growth and leaf development of young tomato plants grown under a combination of red and blue light. Sci Hortic. 2013;153:50-5.

17. Chen MCJ, Fankhauser C. Light signal transduction in higher plants. Annu Rev Genet. 2004:38:87-117.

18. Jiao YLO, Deng XW. Light-regulated transcriptional networks in higher plants. Nat Rev Genet. 2007:8:217-30.

19. Li Y, Xin GF, Wei M, Shi QH, Yang FJ, Wang XF. Carbohydrate accumulation and sucrose metabolism responses in tomato seedling leaves when subjected to different light qualities. Sci Hortic. 2017;225:490-7.

20. Bianchetti RE, Cruz AB, Oliveira BS, Demarco D, Purgatto E, Peres LEP, Rossi M, Freschi L. Phytochromobilin deficiency impairs sugar metabolism through the regulation of cytokinin and auxin signaling in tomato fruits. Sci Rep. 2017;7(1):1-15.

21. Wu Q, Su NN, Shen WB, Cui J. Analyzing photosynthetic activity and growth of Solanum lycopersicum seedlings exposed to different light qualities. Acta Physiol Plant. 2014;36:1411-20.

22. Johkan M, Shoji K, Goto F, Hashida S, Yoshihara T. Blue light-emitting diode light irradiation of seedlings improves seedling quality and growth after transplanting in red leaf lettuce. HortSci. 2010:45:1809-14.

23. Wang LW, Li Y, Xin GF, Wei M, Mi QH, Yang QC. Effects of different proportions of red and blue light on the growth and photosynthesis of tomato seedlings. Chin J Appl Ecol. 2017;28:1595-602.

24. Pu GB, Liu SQ, Liu L, Ren LH. Effects of different light qualities on growthand physiological characteristics of tomato seedlings. Acta Horticulturae Sinica. 2005;32:420-5.

25. Yan MM, Wang ML, Wang HB, Wang YF, Zhao CX. Effects of light quality on photosynthetic pigment contents and photosynthetic characteristics of peanut seedling leaves. Chin J Appl Ecol. 2014;25:483-7.

26. Bondada BR, Syvertsen JP. Leaf chlorophyll, net gasexchange and chloroplast ultra structure in citrus leaves of different nitrogen status. Tree Physiol. 2003;23:553-9

27. Li Y, Varala K, Hudson ME. A survey of the small RNA population during farred light-induced apical hook opening. Front Plant Sci. 2014;5(156):1-11.

28. Li HS, Chen XH, Wang Y, Yao DH, Lin YL, Lai ZX. Exploration of the effect of blue light on microRNAs involved in the accumulation of functional metabolites of longan embryonic calli through RNA-sequencing. J Sci Food Agric. 2019;99:1533-47.

29. Zhou B, Fan PZ, Li YH, Yan HF, Xu QJ. Exploring miRNAs involved in blue/ UV-A light response in Brassica rapa reveals special regulatory mode during seedling development. BMC Plant Biol. 2016;16:111.

30. Zhou XF, Wang GD, Zhang WX. UV-B responsive microRNA genes in Arabidopsis thaliana. Mol Syst Biol. 2007;3:103.

31. Sun ZF, Li M, Zhou Y, Guo TT, Liu Y, Zhang H, Fang YD. Coordinated regulation of Arabidopsis microRNA biogenesis and red light signaling through dicer-like 1 and phytochrome-interacting factor 4. PLoS Genet. 2018;14(3):1-21.

32. Wang B, Sun YF, Song N, Wang XJ, Feng H, Huang LL, Kang ZS Identification of UV-B-induced microRNAs in wheat. Genet Mol Res. 2013; 12(4):4213-21

33. Zhuang J, Zhang J, Hou XL, Wang F, Xiong AS. Transcriptomic, proteomic, metabolomic and functional genomic approaches for thestudy of abiotic stress in vegetable crops. Crit Rev Plant Sci. 2014;33:225-37.

34. Cheah BH, Nadarajah K, Divate MD, Wickneswari R. Identification of four functionally important microRNA families with contrasting differential expression profiles between drought-tolerant and susceptible rice leaf at vegetative stage. BMC Genomics. 2015;16:692.

35. Choudhury FK, Devireddy AR, Azad RK, Shulaev V, Mittler R. Local and systemic metabolic responses during light-induced rapid systemic signaling. Plant Physiol. 2018;178:1461-72.

36. Li M, Liang ZX, He SS, Zeng Y, Jing Y, Fang WK, Wu KC, Wang GY, Ning X, Wang LW, Li S, Tan HW, Tan F. Genome-wide identification of leaf abscission associated microRNAs in sugarcane (Saccharum officinarum L.). BMC Genomics. 2017;18:754

37. Pashkovskiy PP, Kartashov AV, Zlobin IE, Pogosyan SI, Kuznetsov W. Blue light alters miR167 expression and microRNA-targeted auxin response factor genes in Arabidopsis thaliana plants. Plant Physiol Biochem. 2016;104:146-54.

38. Li HS, Lin YL, Chen XH, Bai Y, Wang CQ, Xu XP, Wang Y, Lai ZX. Effects of blue light on flavonoid accumulation linked to the expression of miR393, miR394 and miR395 in longan embryogenic calli. PLoS One. 2018;13:e0191444.

39. Peleg Z, Blumwald E. Hormone balance and abiotic stress tolerance in crop plants. Curr Opin Plant Biol. 2011;14:290-5.

40. Shen Y, Jiang Z, Lu SF, Lin HJ, Gao SB, Peng HW, Yuan GS, Liu L, Zhang ZM, Zhao MJ, Rong TZ, Pan GT. Combined small RNA and degradome sequencing reveals microRNA regulation during immature maize embryo dedifferentiation. Biochem Bioph Res Co. 2013:441:425-30.

41. Su YY, Qiu Y, Zhang XH, Chen XH, Shen D, Wang HP, Li XX. Genome-wide identification of microRNAs associated with taproot development in radish (Raphanus sativus L.). Gene. 2015;569:118-26.

42. Su YC, Zhang YY, Huang N, Liu F, Su WH, Xu LP, Ahmad W, Wu QB, Guo JL, Que YX. Small RNA sequencing reveals a role for sugarcane miRNAs and their targets in response to Sporisorium scitamineum infection. BMC Genomics. 2017;18:325.

43. Xie WF, Huang AZ, Li HM, Feng LZ, Zhang FP, Guo WS. Identification and comparative analysis of microRNAs in Pinus massoniana infected by Bursaphelenchus xylophilus. Plant Growth Regul. 2017;83:223-32.

44. Sarkar D, Maji RK, Dey S, Sarkar A, Ghosh Z, Kundu P. Integrated miRNA and mRNA expression profiling reveals the response regulators of a susceptible tomato cultivar to early blight disease. DNA Res. 2017;24(3):235-50.

45. Zhao GJ, Yu HY, Liu MM, Lu YG, Ouyang B. Identifcation of salt-stress responsive microRNAs from Solanum lycopersicum and Solanum pimpinellifolium. Plant Growth Regul. 2017;83:129-40.

46. Lu XK, Yin ZJ, Wang JJ, Chen XG, Wang DL, Wang S, Guo LX, Fan WL, Chen C, Wang XG, Cui RF, Zhang BL, Han MG, Yang XM, Ye WW. Identification and function analysis of drought-specific small RNAs in Gossypium hirsutum L. Plant Sci. 2019;280:187-96.

47. Candar-Cakir B, Arican E, Zhang BH. Small RNA and degradome deep sequencing reveals drought-and tissue-specific micrornas and their important roles in drought-sensitive and drought-tolerant tomato genotypes. Plant Biotechnol J. 2016;14:1727-46.

48. Vanholme B, Grunewald W, Bateman A, Kohchi T, Ghey-sen G. The tify family previously known as ZIM. Trends Plant Sci. 2007;12(6):239-44.

49. Bai YH, Meng YJ, Huang DL, Qi YH, Chen M. Origin and evolutionary analysis of the plant-specific TIFY transcription factor family. Genomics. 2011;98(2):128-36

50. Shikata M, Matsuda Y, Ando K, Nishii A, Takemura M, Yokota A, Kohchi T. Characterization of Arabidopsis ZIM, a member of a novel plant-specific GATA factor gene family. J Exp Bot. 2004:55(397):631-9.

51. White DWR. PEAPOD regulates lamina size and curvature in Arabidopsis. Proc Natl Acad Sci U S A. 2006;103(35):13238-43.

52. Chung HS, Koo AJK, Gao XL, Jayanty S, Thines B, Jones AD, Howe GA. Regulation and function of Arabidopsis JASMONATE ZIM-domain genes in response to wounding and herbivory. Plant Physiol. 2008;146(3):952-64.

53. Ye HY, Du H, Tang N, Li XH, Xiong LZ. Identification and expression profiling analysis of TIFY familygenes involved in stress and phytohormone responses inrice. Plant Mol Biol. 2009;71(3):291-305.

54. Zhang F, Yao J, Ke JY, Zhang L, Lam VQ, Xin XF, Zhou XE, Chen J, Brunzelle J, Griffin PR, Zhou M, Xu HE, Melcher K, He SY. Structural basis of JAZ repression of MYC transcription factors in jasmonate signaling. Nat. 2015; 525(7568):269-73

55. Thatcher LF, Cevik V, Grant M, Zhai B, Jones JDG, Man-ners JM, Kazan K Characterization of a JAZ7activation-tagged Arabidopsis mutant with increased susceptibility to the fungal pathogen Fusarium oxysporum. J Exp Bot. 2016;67(8):2367-86.

56. Komatsu K, Nishikawa Y, Ohtsuka T, Taji T, Quatrano RS, Tanaka S, Sakata Y. Functional analyses of the ABl1-related protein phosphatase type $2 \mathrm{C}$ reveal 
evolutionarily conserved regulation of abscisic acid signaling between Arabidopsis and the moss Physcomitrella patens. Plant Mol Biol. 2009;70:327-40.

57. Yu LP, Simon EJ, Trotochaud AE, Clark SE. POLTERGEIST functions to regulate meristem development downstream of the CLAVATA loci. Dev. 2000;127:1661-70.

58. Xiang Y, Sun X, Gao S, Qin F, Dai M. Deletion of an endoplasmic reticulum stress response element in a ZMPP2C-A gene facilitates drought tolerance of maize seedlings. Mol Plant. 2017;10:456-69.

59. Zhang H, Li W, Mao X, Jing R, Jia H. Differential activation of the wheat SnRK2 family by abiotic stresses. Front Plant Sci. 2016;7:420.

60. Zhang F, Wei Q, Shi J, Jin X, He Y, Zhang Y, Luo Q, Wang Y, Chang J, Yang $\mathrm{G}, \mathrm{He}$ G. Brachypodium distachyon BdPP2CA6 interacts with BdPYLs and BdSnRK2 and positively regulates salt tolerance in transgenic Arabidopsis. Front Plant Sci. 2017:8:264.

61. Zhang J, Li X, He Z, Zhao X, Wang Q, Zhou B, Yu D, Huang X, Tang D, Guo $X$, Liu X. Molecular character of a phosphatase 2C (PP2C) gene relation to stress tolerance in Arabidopsis thaliana. Mol Biol Rep. 2013;40:2633-44.

62. Cao J, Jiang M, Li P, Chu Z. Genome-wide identification and evolutionary analyses of the PP2C gene family with their expression profiling in response to multiple stresses in Brachypodium distachyon. BMC Genomics. 2016;17:175.

63. Žižková E, Dobrev PI, Muhovski Y, Hošek K, Hoyerová K, Haisel D, Procházková D, Lutts S, Motyka V, Hichri I. Tomato (Solanum lycopersicum L.) SIIPT3 and SIIPT4 isopentenyltransferases mediate salt stress response in tomato. BMC Plant Biol. 2015;15:85.

64. Gao CX. Biosynthetic mechanism of indole alkaloids under ultraviolet irradiation and cloning and prokaryotic expression analysis of CtIPT in Clematis terniflora DC [M. D. dissertation]. Hangzhou: Zhejiang University; 2016.

65. Nishiyama R, Le DT, Watanabe Y, Matsui A, Tanaka M, Seki M, YamaguchiShinozaki K, Shinozaki K, Tran LP. Transcriptome analyses of a salt-tolerant cytokinin-deficient mutant reveal differential regulation of salt stress response by cytokinin deficiency. PLoS One. 2012;7(2):e32124.

66. Langmead B, Trapnell C, Pop M, Salzberg SL. Ultrafast and memory-efficient alignment of short DNA sequences to the human genome. Genome Biol. 2009;10(3):R25.

67. Friedlander MR, Mackowiak SD, Li N, Chen W, Rajewsky N. miRDeep2 accurately identifies known and hundreds of novel microRNA genes in seven animal clades. Nucleic Res. 2012;40:37-52.

68. Zhang Z, Jiang L, Wang J, Gu P, Chen M. Mtide: an integrated tool for the identification of miRNA-target interaction in plants. Bioinform. 2015:31(2):290-1.

69. Fahlgren N, Howell MD, Kasschau KD, Chapman EJ, Sullivan CM, Cumbie JS, Givan SA, Law TF, Grant SR, Dangl JL, Carrington JC. High-throughput sequencing of Arabidopsis microRNAs: evidence for frequent birth and death of MIRNA genes. PLoS One. 2007;2(2):e219.

70. Ma XR, Li L, Liu JH, Yang MJ, Chen J, Liang Q, Wu SH, Li YY. Identification and differentially expressed analysis of microRNA associated with dormancy of pear flower buds. Acta Horticulturae Sinica. 2018;45(11):20189-2105.

71. Allen $\mathrm{E}$, Xie Z, Gustafson AM, Carrington JC. microRNA-directed phasing during transacting siRNA biogenesis in plants. Cell. 2005;121(2):207-21.

72. Ashburner M, Ball CA, Blake JA, Botstein D, Butler H, Cherry JM, Davis AP, Dolinski K, Dwight SS, Eppig JT, Harris MA, Hill DP, Issel-Tarver L, Kasarskis A, Lewis S, Matese JC, Richardson JE, Ringwald M, Rubin GM, Sherlock G. Gene ontology: tool for the unification of biology. Nat Genet. 2000;25:25-9.

73. Kanehisa M, Goto S, Kawashima S, Okuno Y, Hattori M. The KEGG resource for deciphering the genome. Nucleic Acids Res. 2004;32:D277-80.

\section{Publisher's Note}

Springer Nature remains neutral with regard to jurisdictional claims in published maps and institutional affiliations.

Ready to submit your research? Choose BMC and benefit from:
- fast, convenient online submission
- thorough peer review by experienced researchers in your field
- rapid publication on acceptance
- support for research data, including large and complex data types
- gold Open Access which fosters wider collaboration and increased citations
- maximum visibility for your research: over 100M website views per year
At BMC, research is always in progress.
Learn more biomedcentral.com/submissions

